\title{
Durability of Defense Waste Processing Facility Glasses Within the Purex Range of Compositions (U)
}

May, 1995

Westinghouse Savannah River Company Savannah River Technology Center Aiken, SC 29808

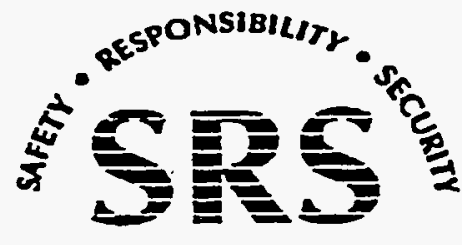




\section{DISCLAIMER}

This report was prepared by Westinghouse Savannah River Company (WSRC) for the United States Department of Energy under Contract No. DE-AC09-89SR18035 and is an account of work performed under that contract. Reference herein to any specific commercial product, process, or service by trademark, name, manufacturer or otherwise does not necessarily constitute or imply endorsement, recommendation, or favoring of same by WSRC or by the United States Government or any agency thereof. The views and opinions of the authors expressed herein do not necessarily state or reflect those of the United States Government or any agency thereof. 


\section{DISCLAIMER}

Portions of this document may be illegible in electronic image products. Images are produced from the best available original document. 
Key Words:

DWPF

Durability

PCT

Purex

Retention: Lifetime

\section{Durability of Defense Waste Processing Facility Glasses Within the Purex Range of Compositions (U)}

T. B. EDWARDS

A. L. KIELPINSKI

May, 1995

Westinghouse Savannah River Company Savannah River Technology Center Aiken, SC 29808

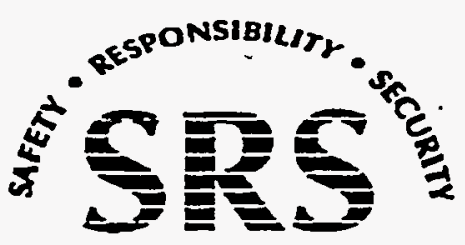

SAVANNAH RIVER SITE

PREPARED FOR THE U.S. DEPARTMENT OF ENERGY UNDER CONTRACT NO. DE-AC09-89SR18035 DISTRIBUTION OF THIS DOCUMENT IS UNLIMITED 
WSRC-TR-95-0209

Rev. 0

Project:

Document:

Title:
DWPF

WSRC-TR-95-0209

Durability of Defense Waste Processing Facility

Glasses Within the Durex Range of Compositions (U)

Approvals:

O. B. Edwards . 5-5-95

T. B. Edwards, Author

A.L.Kisicic.

A. L. Kielpinski, Author

$\frac{5 / 5 / 95}{\text { Date }}$

Doc. Weller

J. Weber, Technical Reviewer

$\frac{5 / 5 / 95}{\text { Date }}$

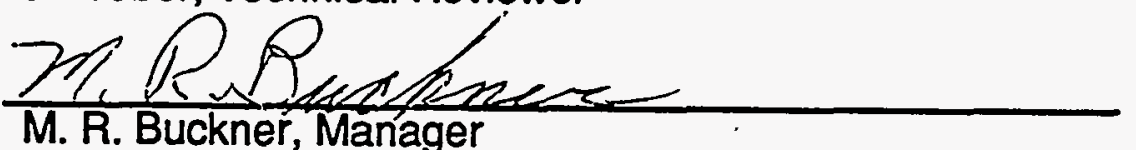

$\frac{5 / 5 / 95}{\text { Date }}$

Edwards $\gg$.

R. E. Edwards, DWPF Customer

$\frac{5 / 5 / 95}{\text { Date }}$ 


\section{Introduction.}

Processing in the Defense Waste Processing Facility (DWPF) is controlled by constraints on predicted properties of the product glass. One of these properties is chemical durability, which is measured as the response of various glass constituents to the seven-day Product Consistency Test (PCT) [1]. As currently implemented into the DWPF's Product Composition Control System (PCCS), the response of boron is taken as representative of all of the constituent responses, and control is in terms of the boron response. This response, in normalized units and in log scale, is taken to be a linear function of the glass's free energy of hydration, $\Delta G . \Delta G$ is a parameter which represents the sum of influences on durability of the various glass oxide components.

A generalized relationship between these two variables is documented in [2]. This relationship appears to underpredict releases for glasses in the so-called "Purex" range of compositions which comprises a worst-case DWPF operating range. Using a similar methodology as in [2], a linear regression specific to Purex compositions is developed herein.

\section{Summary}

A generalized relationship between the normalized PCT boron release and the free energy of hydration of a glass is documented in [2]. This relationship appears to underpredict releases for glasses in the so-called "Purex" range of compositions which comprises a worst-case DWPF operating range. Using a similar methodology as in [2], a linear regression specific to Purex compositions is developed herein. The Purex correlation was developed by considering all of the available relevant data (119 glasses), then fitting to an optimized subset of the data ( 30 points out of the total 119 ). The result is:

$$
\log _{10}\left(N L_{B}\right)=-1.494178-0.292675 \Delta G_{p}
$$

with $R^{2}=0.91$ and $R M S E=0.20$. The value of $\Delta G_{p}$ at which the upper $95 \%$ tolerance limit (at $95 \%$ confidence) for this regression reaches the nominal release value for Environmental Assessment (EA) glass is approximately -7.44 $\mathrm{kcal} / \mathrm{mol}$. This represents the minimum value of $\Delta G_{p}$ which will yield acceptable durability. Therefore, Purex compositions to be processed in DWPF must be such that their $\Delta G_{p}$ exceeds this value.

\section{Discussion}

The relationship between the boron release and the free energy of hydration $\Delta G$ can be expressed as:

$$
\log _{10}\left(N L_{B}\right)=a+b \Delta G_{p}
$$

where $N L_{B}$, the normalized boron response, is 


$$
N L_{B}[g / l]=\frac{C_{B}[p p m]}{10 f_{B}}
$$

with $C_{B}$ the concentration of boron in the PCT leachant and $f_{B}$ the mass fraction of boron in the glass. For consistency with previous work, the notation $\Delta G_{p}$ will be used to denote the "preliminary" estimation of $\Delta G$ (i.e.; where $\mathrm{pH}$ effects are not accounted for). This is the estimation of $\Delta G$ which is implemented into DWPF control. $\Delta G_{p}$ is taken as an ideal-mixture property, i.e.,

$$
\Delta G=\sum_{i} x_{i} \Delta G_{i}
$$

where the appropriate hydration reactions for each glass oxide species must be chosen to yield the individual $\Delta G_{i}$ values. A detailed discussion of the methodology for computing $\Delta G_{p}$ is available in [2]. A linear regression over available data was performed in [3], yielding the following coefficients:

$$
\log _{10}\left(N L_{B}\right)=-1.8253-0.271 \Delta G_{p}
$$

This database of 124 glass compositions included 21 glasses simulating Purex operation; all but seven of these glasses were excluded from the regression fit, however, for reasons detailed in [2]. The final regression equation was based on 93 glasses, including these seven.

To improve predictability for operations involving (unremediated) Purex sludge, all available data pertaining to such operations (a total of 119 glass compositions) was assembled. This included 29 glasses from the "Purex variability" study performed in [3], 54 glasses from the "Purex parametric" study $[4,5]$, and 15 glasses which were fabricated in the IDMS and/or were involved in crucible studies of remediated IDMS glass compositions [2,6]. All 21 glasses from among the original 124 glasses assembled in [2] were also included, since they represent part of the compositional range of interest, and it is unclear that their original exclusion was warranted.

Figure 1 shows the mole percent distributions of some of the glass component oxides for both the database of 93 glasses used in [2] and the 119 Purex glasses examined in this work. The Purex database has a lower $\mathrm{Al}_{2} \mathrm{O}_{3}$ oxide content than the 93-glass database used to obtain the coefficients shown in equation (4). Although sometimes referred to as "high-iron" compositions, the mean $\mathrm{Fe}_{2} \mathrm{O}_{3}$ content is only slightly higher in the Purex database (the median value is slightly lower). The mean $\mathrm{B}_{2} \mathrm{O}_{3}$ content of the Purex database is slightly lower, though this is influenced by a few outlying points in the equation (4) database. The Purex database is also somewhat higher in $\mathrm{Li}_{2} \mathrm{O}$, slightly lower in $\mathrm{Na}_{2} \mathrm{O}$, and about the same in $\mathrm{SiO}_{2}$. Although $\mathrm{ZrO}_{2}$ is only present in trace amounts in both databases, it was significantly higher in the Purex database. 
Since the data were acquired by assembling all available relevant information, it was desirable to perform the actual regression over a subset of these data, using the remainder of the database to validate the regression so obtained. Thirty data points were be selected from the 119 available glasses to perform the initial model fit.

In considering ways to select these 30 points, such as a simple random sample, the D-optimality criterion (described in the JMP® User's Manual [7]) came to mind. The "D-optimal design" aid is typically used to search for an optimal design for an experiment, selecting points from the candidates in an available data set. The optimality criteria used to select the points for a design is the Doptimality criterion, which seeks to maximize the determinant of the information matrix of the design. Simply stated, this is equivalent to selecting the points which minimize the variances of the estimates of the parameters in equation (1).

If the $\mathbf{3 0}$ glasses to be used in the regression are selected to minimize the resulting variances of the estimates of the parameters in equation (1), then those glasses corresponding to the extreme values of $\Delta G_{p}$ should be selected. Specifically, the glasses with the fifteen largest $\Delta G_{p}$ 's and the fifteen smallest $\Delta G_{p}$ 's were selected for use in the initial fitting of equation (1). Most of the points in the fit were derived from the 54-point "parametric" study (high end of $\Delta G_{p}$ range) and from the (unremediated) Purex 5 IDMS runs (low end of $\Delta G_{p}$ range), with a few points from the other sources.

Figure 2 provides the results of fitting these data to equation (1). The optimized dataset yielded the following regression equation:

$$
\log _{10}\left(N L_{B}\right)=-1.494178-0.292675 \Delta G_{p}
$$

Equation (5) has an adjusted correlation coefficient $\left(R^{2}\right)$ of 0.91 and a root mean square error (RMSE) of 0.20 .

Figure 3 shows equation (5) with the associated $95 \%$ confidence band for individual prediction. All 119 data points are shown for comparison. A few of the fitting data points are labeled for information, where PX-5 denotes an IDMS Purex 5 run, $P-i$ is the $i$-th point of the "parametric" study of $[4,5]$, and the label "PUREX" corresponds to the Purex composition in the Waste Compliance Plan [8]. As shown in the figure, most of the data fall within the $95 \%$ confidence bands for individual prediction, and virtually all the data fall below the upper limit. That is, equation (5), based on 30 points tends to predict somewhat conservatively for the remaining 89 points of the database.

Figure 4 provides a more detailed look at the difference between the actual durability results and the predictions for the 89 glass compositions not used in the fitting of equation (5). The distribution of these residuals is reasonably "bellshaped," and the average values is -0.09 (the model over predicts, on average). The standard deviation of 0.27 is larger (significantly, at the 0.05 level) than the 
root mean square error of 0.20 of the original fit. This result is well within expectations for a validation of equation (5).

Given that the model predicts the entire database quite reasonably, it is valid to refit the coefficients using all of the data rather than the original 30-point subset. Figure 5 shows this fit $\left(R^{2}=0.70\right.$, RMSE $\left.=0.26\right)$, which is given by:

$$
\log _{10}\left(N L_{B}\right)=-1.672714-0.307967 \Delta \dot{G}_{p}
$$

While the slope of equation (6) is virtually identical to that of equation (5), the intercept is shifted down by about 0.2 (corresponding to predictions of $20 \%$ lower normalized boron release). We note that the points which fell below the lower confidence band of equation (5), and which contribute to lowering the intercept in equation (6), tend to be glasses which were made earlier in time (the WCP Purex composition, and the pilot-scale Purex 1 and 2 melter runs). Assuming that later investigations are based on more current definitions of likely Purex compositions, equation (5) may be a more accurate representation of the Purex compositions of current interest.

\section{Limits for DWPF Prediction}

For conservative implementation into DWPF, a 95\% tolerance limit with 95\% confidence for multiple predictions is desired, rather than the $95 \%$ confidence limit for an individual prediction which was shown on the preceding figures.

The tolerance limits for multiple predictions will be wider, hence more restrictive. Using equation (5) and the database of 30 glass compositions upon which it was founded, an upper tolerance interval covering $95 \%$ of the predictions with 95\% confidence was developed using the approach presented by Miller [9]. This type of prediction interval is appropriate when the total number of predictions to be handled by an equation such as (5) is large or unknown.

The results of this fit lead to the upper 95\% tolerance bound (with $95 \%$ confidence) given by the expression

$$
\begin{aligned}
& -1.494178-0.292675 \Delta G_{p}+ \\
& s\left\{\left(2 F_{2,28}^{\alpha}\right)^{1 / 2}\left[\frac{1}{30}+\frac{\left(\Delta G_{p}-\overline{\Delta G_{p}}\right)^{2}}{\sum_{i=1}^{30}\left(\left(\Delta G_{p}\right)_{i}-\overline{\Delta G_{p}}\right)^{2}}\right]^{1 / 2}+z(p)\left(\frac{28}{\chi_{(\alpha / 2), 28}^{2}}\right)^{1 / 2}\right\}
\end{aligned}
$$

where $\Delta G_{p}$ represents a new value for which a prediction it to be made, 
S represents the root mean square error of the fit for equation (4),
$\overline{\Delta G_{p}}$
represents the average of the $\left(\Delta G_{p}\right)_{i}$ 's (the values used in fitting equation (2)),
$F_{2,28}^{\alpha}$
represents the upper 100a percent point of the $F$
distribution with 2 degrees of freedom in the numerator and 28 degrees of freedom in the denominator,
$\chi_{(\alpha / 2), 28}^{2}$
represents the lower $(\alpha / 2)$ percentile point of a $\chi^{2}$
$z(p)$
distribution with 28 degrees of freedom, represents the one-sided $p$ percentile point of the unit normal distribution (in this situation $p$ equals 0.95 ), and
$\alpha \quad$ represents the confidence level (in this situation a equals 0.95).

The information necessary to determine these tolerance limits was available from the JMP ${ }^{\circledR}$ analysis resulting from the fitting of data to equation (5). The equation of these limits is given by

$$
\begin{aligned}
& -1.494178-0.292675 \Delta G_{p}+\{\sqrt{2 \times 3.3404} \times \\
& \sqrt{0.03935581 \times\left(0.36303149+0.09674605 \Delta G_{p}+0.00709725\left(\Delta G_{p}\right)^{2}\right)} \\
& \left.+0.198383 \times 1.64485 \times \sqrt{\frac{28}{15.307861}}\right\}
\end{aligned}
$$

The same approach was used to determine a similar upper tolerance limit for the results of fitting equation (6). Figure 6 shows equations (5) and (6) (denoted "Initial Data" and "All Data" in the figure). Also shown are the upper tolerance limits (UTL) associated with each of these equations. Despite the larger RMSE of equation (6), which tends to widen the tolerance limit, the limit for the original fit of 30 points, denoted "UTL Initial Data," is still slightly higher--hence, more conservative. Both UTL curves conservatively bound all of the data in the Purex database; however, equation (4) and its UTL are recommended for use in DWPF.

Also shown in Figure 6 is a horizontal line at 1.2227, the nominal value of $\log _{10}\left(N L_{B}\right)$ for the limiting EA glass: Assuming that use of this nominal descriptor for EA glass is sufficiently conservative for DWPF implementation, the point where this horizontal line crosses line denoted "UfL Initial Data" yields 
the limiting value of $\Delta G_{p}$. The intersection occurs at approximately $\Delta G_{p}=-7.44$ $\mathrm{kcal} / \mathrm{mol}$. Note that a more conservative implementation would be to define a limiting $\Delta G_{p}$ value based on the lower $95 \%$ confidence value of the EA glass, rather than the nominal value as shown here. Our current understanding is that this extra conservatism is not warranted for this application.

\section{Conclusions}

A correlation for predicting glass durability for "Purex" type glasses was developed for use in DWPF. The correlation is in terms of the "preliminary" free energy of hydration described in [2] and is therefore consistent with the previous development in [2] of a "general use" correlation. The Purex correlation was developed by considering all of the available relevant data, then fitting to an optimized subset of the data (30.points out of the total 119). The result is:

$$
\log _{10}\left(N L_{B}\right)=-1.494178-0.292675 \Delta G_{p}
$$

with $R^{2}=0.91$ and $R M S E=0.20$. Comparing all 119 points to this regression as a validation of equation (5) shows that the equation is a conservative predictor of the overall database. Of the few points falling outside of the $95 \%$ confidence bands for individual prediction, most fell below the lower band.

For implementation into DWPF, the tolerance limit for multiple predictions was also determined. Again, the upper tolerance limit associated with equation (4) was a conservative predictor of all of the data. The value of $\Delta G_{p}$ at which this limit reaches the nominal release value for EA glass is approximately -7.44 $\mathrm{kcal} / \mathrm{mol}$. This represents the minimum value of $\Delta G_{p}$ which will yield acceptable durability. Therefore, Purex compositions to be processed in DWPF must be such that their $\Delta G_{p}$ exceeds this value.

\section{Refërences}

[1] Jantzen, C. M., Bibler, N. E., Beam, D. C., and Ramsey, W. G., "Nuclear Waste Glass Product Consistency Test (PCT)--Version 7.0" (U), WSRC-TR-90539, Revision 7, 1995.

[2] Jantzen, C. M., Pickett, J., and Beam, D. C., "Process/Product Models for the Defense' Waste Processing Facility (DWPF): Part I. Predicting Glass Durability from Composition Using a Thermodynamic Hydration Energy Reaction Model (THERMO)" (U), WSRC-TR-93-672, May, 1995.

[3] Pareizs, J. M., "Purex Sludge Durability Crucible Studies" (U), WSRC-TR95-0154, 1995.

[4] E. W. Holtzscheiter, "PCT Results of Purex Variability Study Samples 1 through 20," SRT-DWP-95-0023, April 20, 1995; E. W. Holtzscheiter, "PCT 
Results of Purex Variability Study Samples 21 through 29," SRT-DWP-95-0020, April 13, 1995; remaining PCT results recorded in WSRC-NB-92-151.

[5] E. W. Holtzscheiter, "Elemental Results for WP-15 Purex Glass

Parametric Study," SRT-PTD-95-0037, May 2, 1995

[6] Ramsey, W. G., "Production of and Remediation of Low-Sludge, Simulated Purex Waste Glasses, II: Effects of Sludge Oxide Additions on Glass Durability" (U), WSRC-TR-93-414, Rev. 0, July, 1993.

[7] SAS Institute Inc., JMP ${ }^{\otimes}$ Statistics and Graphics Guide, Version 3 Edition, SAS Institute, Inc., Cary NC, 1994.

[8] DWPF Waste Form Compliance Plan, Rev. 1, USDOE Document WSRCIM-91-116-0, 1992.

[9] Miller, Jr., Rupert G., Simultaneous Statistical Inference, Second Edition, Springer-Verlag; New York, 1980, pages 123-124. 


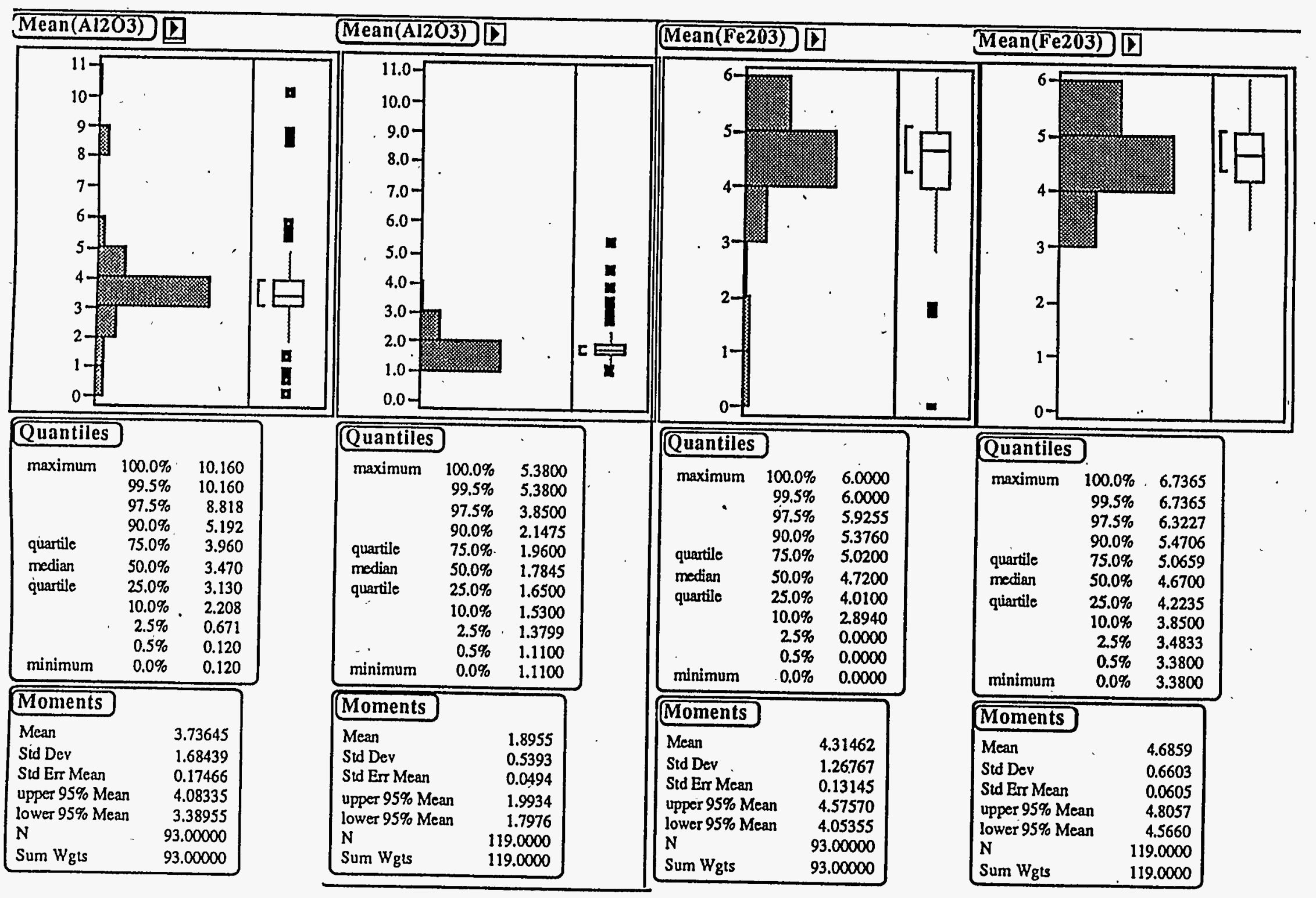

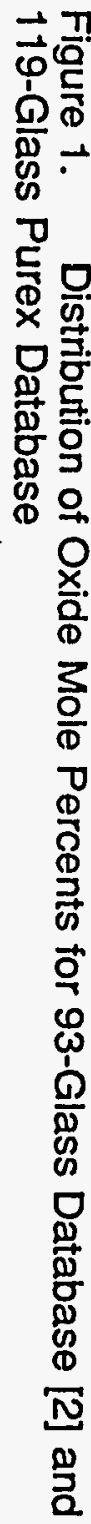



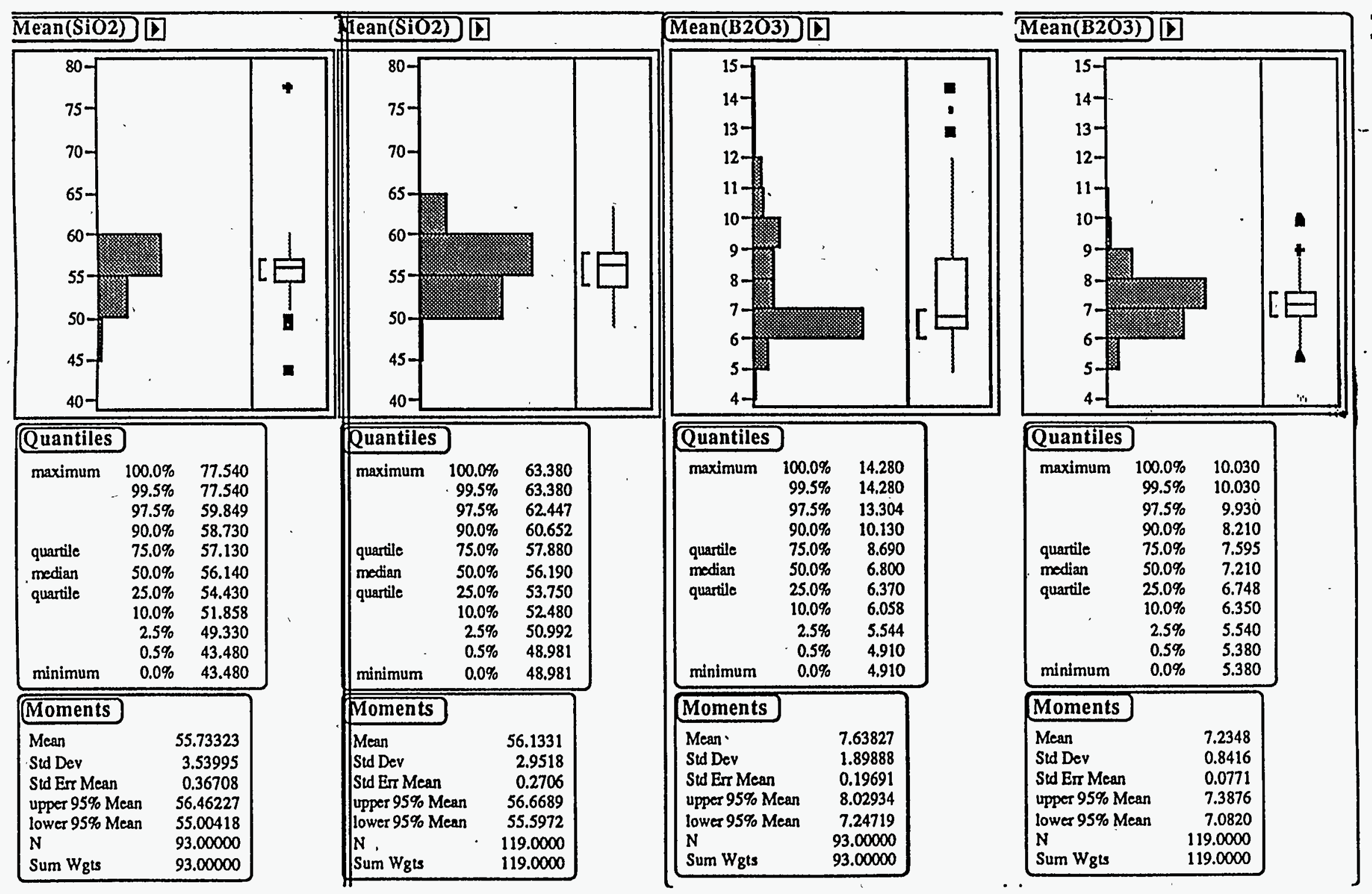

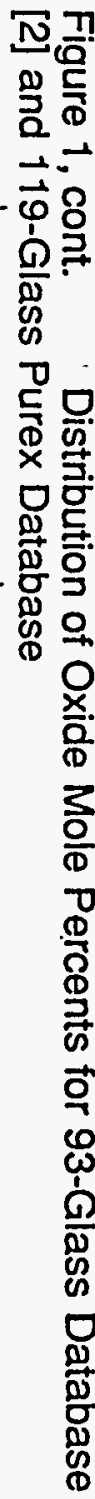

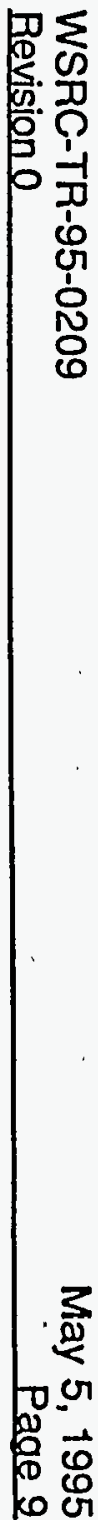


Figure 1, cont. Distribution of Oxide Mole Percents for 93-Glass Database [2] and 119-Glass Purex Database

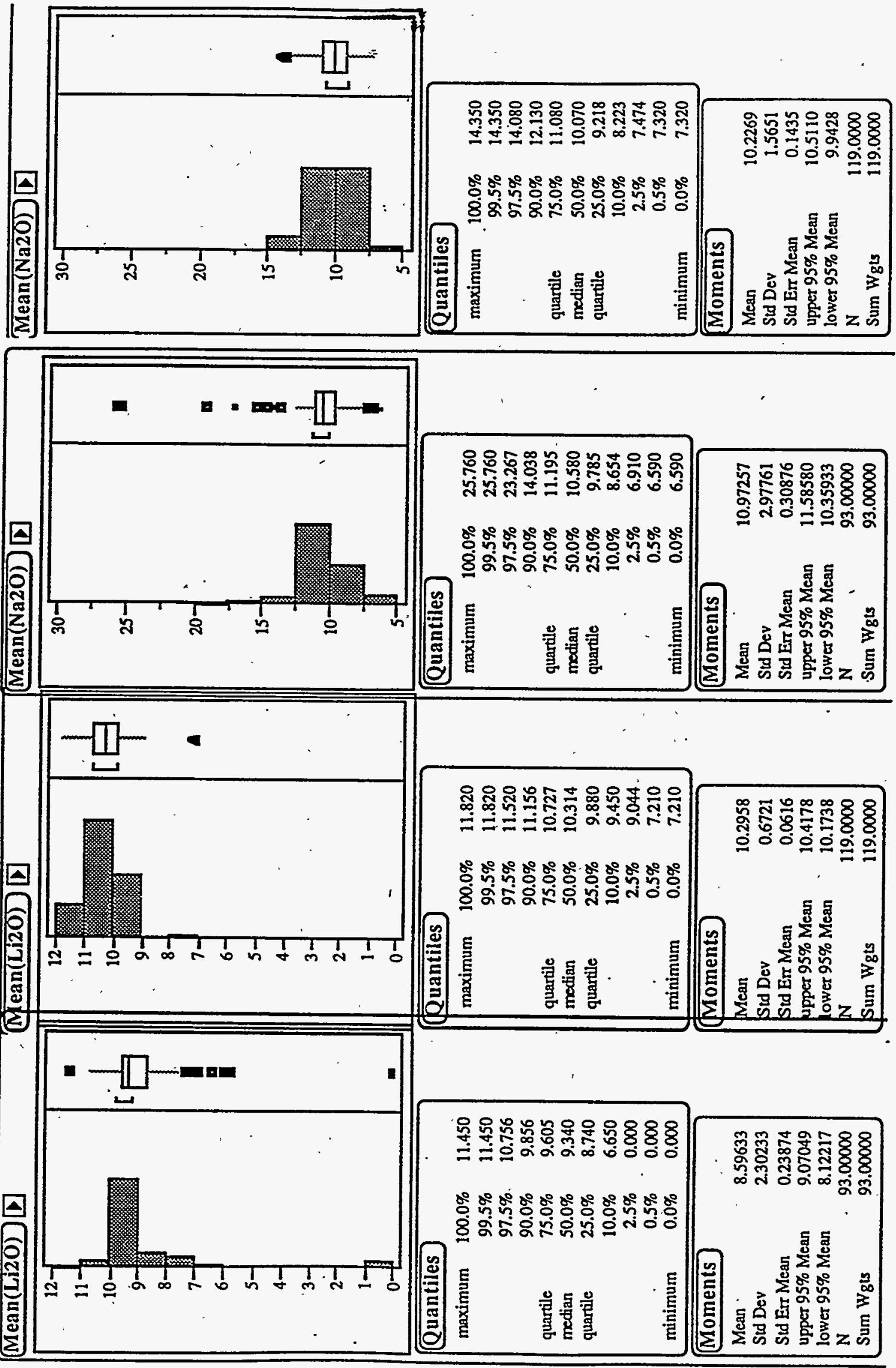


Figure 1, cont. Distribution of Oxide Mole Percents for 93-Glass Database [2] and 119-Glass Purex Database

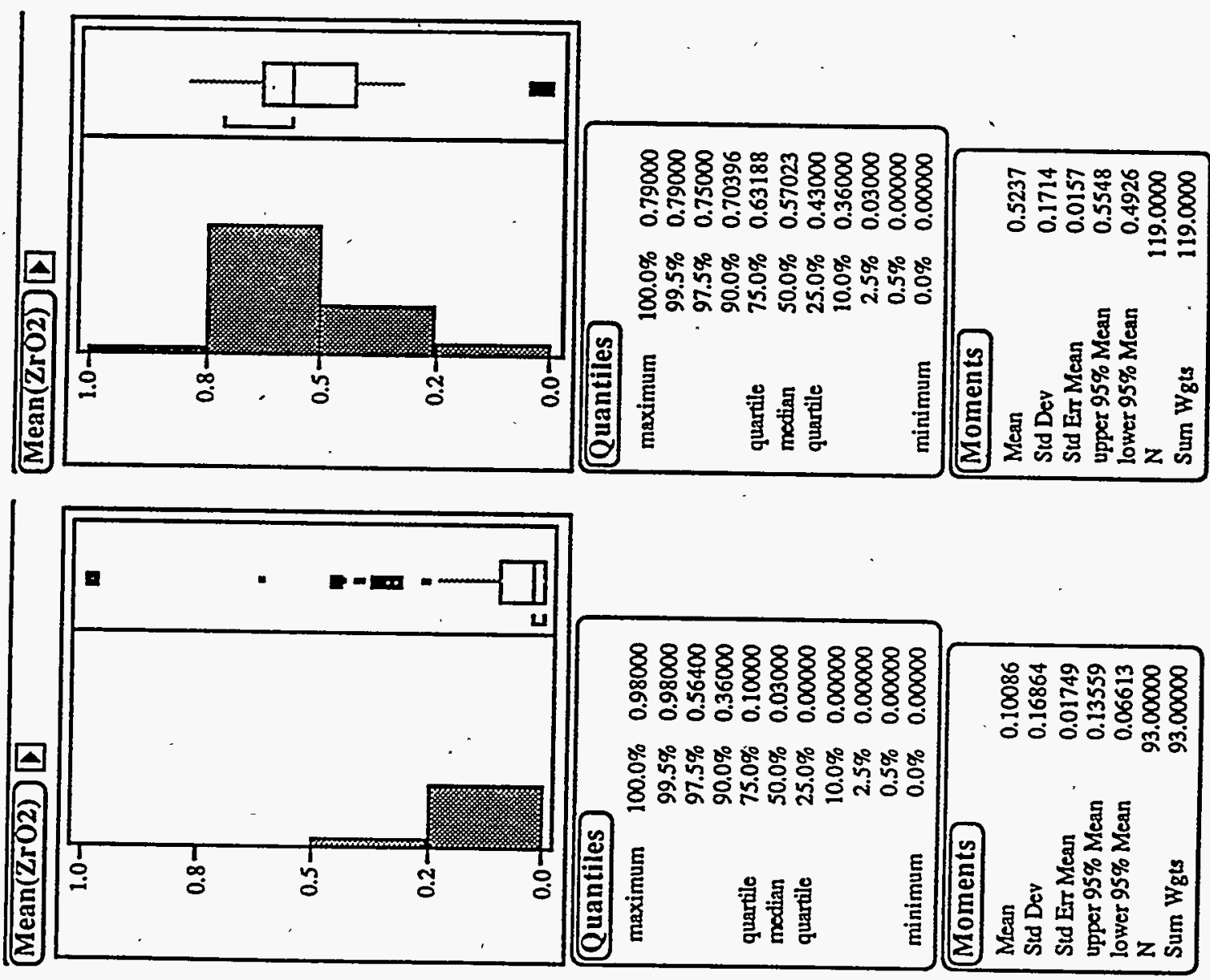


Figure 2. Fitting of the Durability Model for the Initial 30 Data Points

$$
=
$$

$\begin{array}{lr}\text { Response: } \log (\mathrm{NLB}) & \\ \quad \text { Summary of Fit } & \\ \text { RSquare } & 0.916336 \\ \text { RSquare Adj } & 0.913348 \\ \text { Root Mean Square Error } & 0.198383 \\ \text { Mean of Response } & 0.500618 \\ \text { Observations (or Sum Wgts) } & 30\end{array}$

\begin{tabular}{lrrrr}
\multicolumn{5}{c}{ Parameter Estimates } \\
Term & Estimate & Std Error & t Ratio & Prob $>|t|$ \\
Intercept. & -1.494178 & 0.11953 & -12.50 & 0.0000 \\
Calc Del G. & -0.292675 & 0.01671 & -17.51 & 0.0000
\end{tabular}

\begin{tabular}{lrrrrr}
\multicolumn{7}{c}{ Effect Test } & & \\
Source & Nparm & DF & Sum of Squares & F Ratio & Prob $>$ F \\
Calc DelG & 1 & 1 & 12.069256 & 306.6703 & 0.0000
\end{tabular}


Figure 3: $\quad$ Plot of Fit to the Initial Data

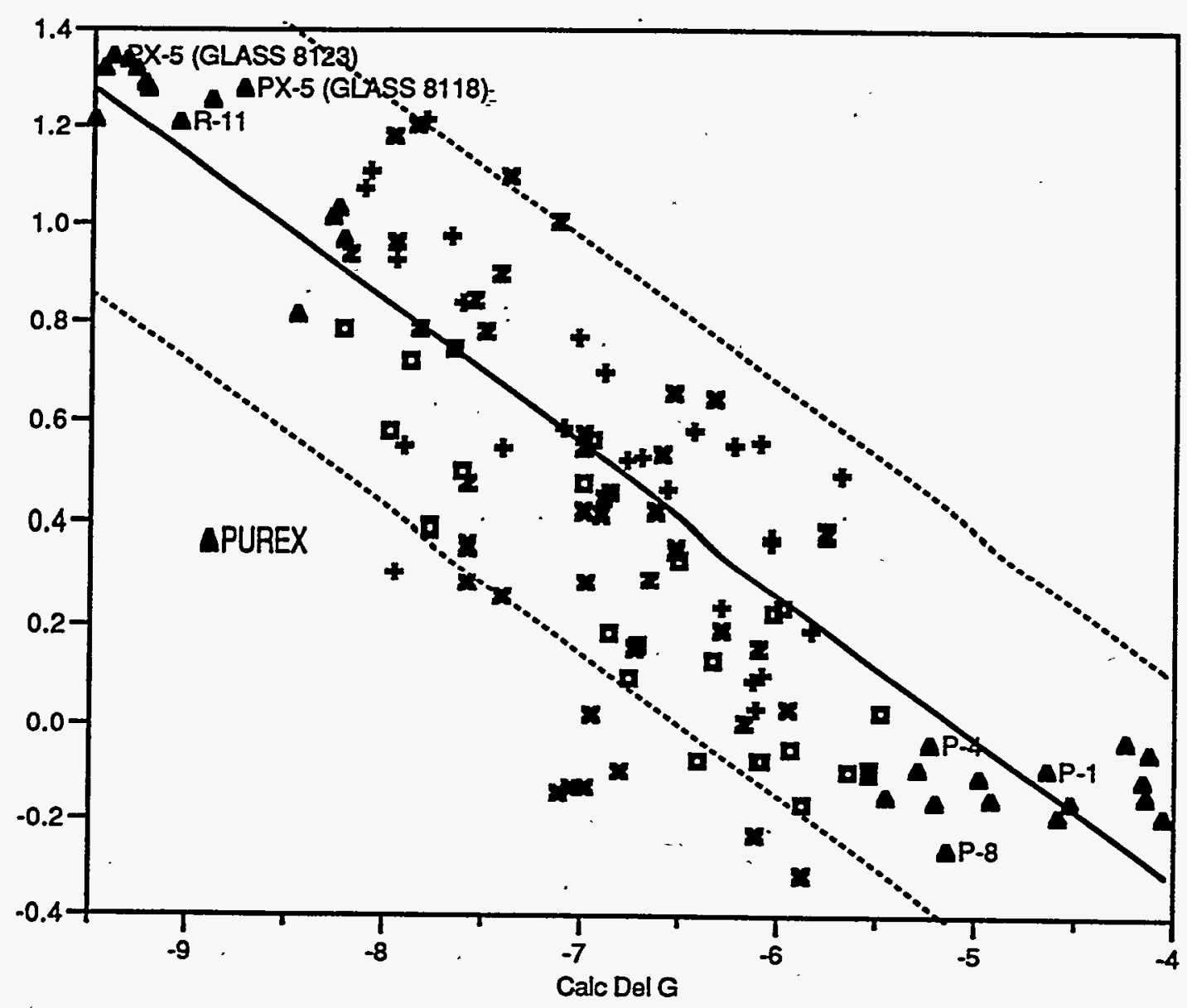


Figure 4. Analysis of the Residuals of Unfitted Data to "Best" Fit Residual $\log$ (NLB) Inltial

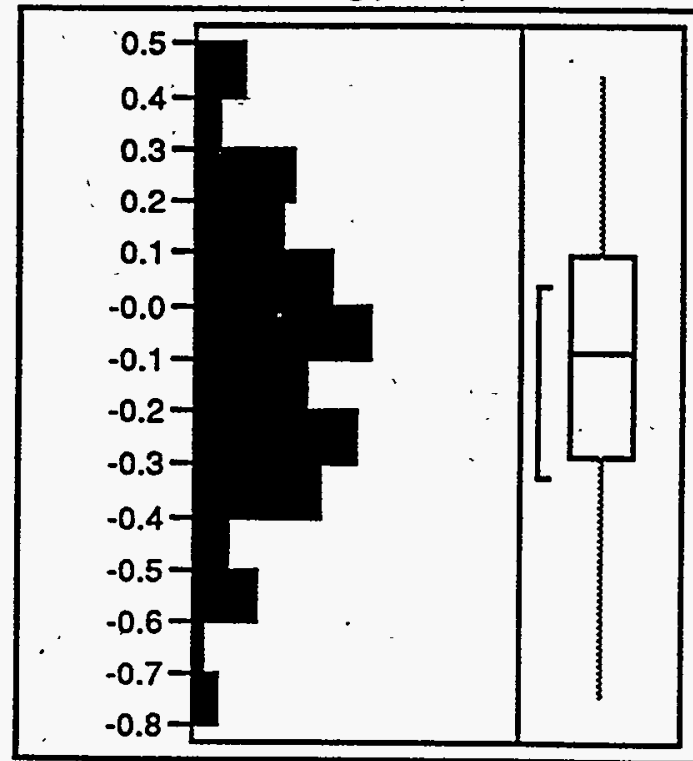

\section{Quantiles}

maximum $100.0 \%$ $99.5 \%$

$97.5 \%$ $90.0 \%$

quartile

$75.0 \%$

median

quartile

$50.0 \%$

$25.0 \%$

$10.0 \%$

$2.5 \%$

$0.5 \%$

minimum
0.43451

0.43451

0.42234

0.23832

0.09649

$-0.0854$

$-0.2829$

$-0.4524$

$-0.7005$

$-0.7296$

$-0.7296$

\section{Moments}

Mean

Std Dev

$-0.09892$

Std Err Mean

0.27250

0.02889

upper 95\% Mean

$-0.04151$

lower 95\% Mean

$N$

$-0.15632$

89.00000

Sum Wgts . 
Figure 5. Durability Regressed on $\Delta G_{p}$ Using All Purex Data log(NLB) By Calc Del G

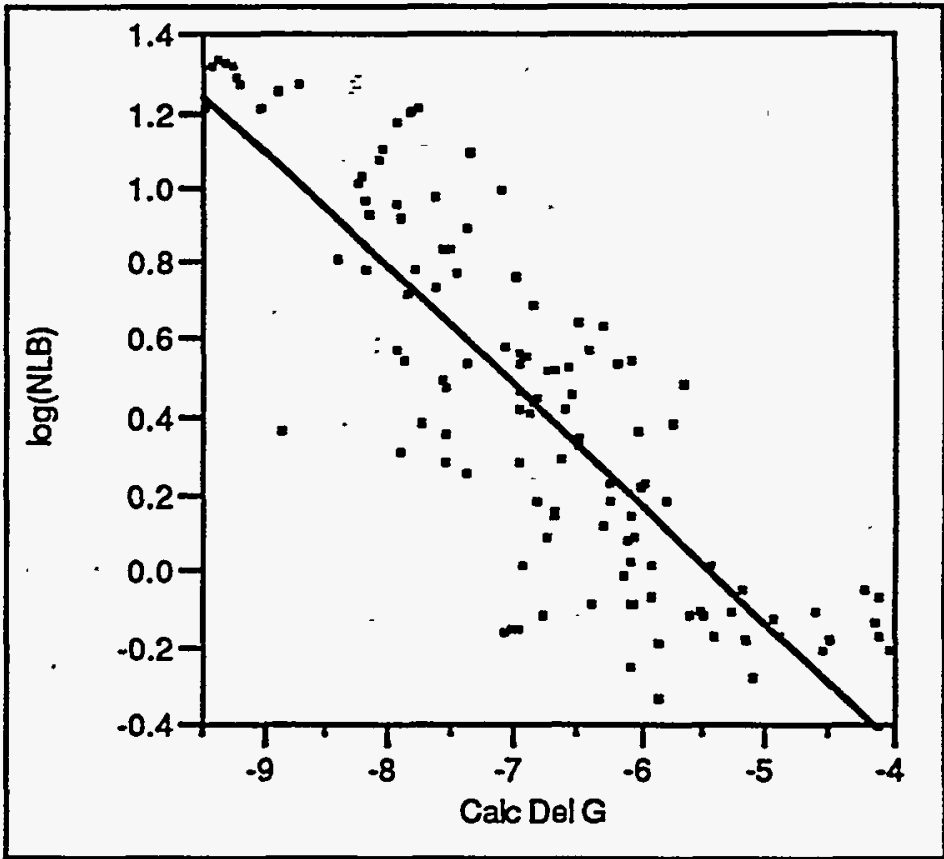

Linear Fit Summary of Fit RSquare

RSquare Adj

0.697678

Root Mean Square Error

Mean of Response

0.695094

Observations (or Sum Wgts)

0.258392

0.432965

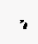

Analysis of Variance

$\begin{array}{lrrrrr}\text { Source } & \text { DF } & \text { Sum of Squares } & \text { Mean Square } & \text { F Ratio } \\ \text { Model } & 1 & 18.027281 & 18.0273 & 270.0045 \\ \text { Error } & 117 & 7.811692 & 0.0668 & \text { Prob }>\text { F } \\ \text { CTotal } & 118 & 25.838973 & & 0.0000\end{array}$

\begin{tabular}{lrrrr}
\multicolumn{5}{c}{ Parameter Estimates } \\
Torm & Estimate & Std Error & t Ratio & Prob $>|t|$ \\
Intercept & -1.672714 & 0.13032 & -12.84 & 0.0000 \\
Calc Del G & -0.307967 & 0.01874 & -16.43 & 0.0000
\end{tabular}


Figure 6: Initial and All Data Models and Tolerance Limits

$y$ axis is $\log _{10} N L(B)$

+ points are the actual durability values for the Purex Glasses

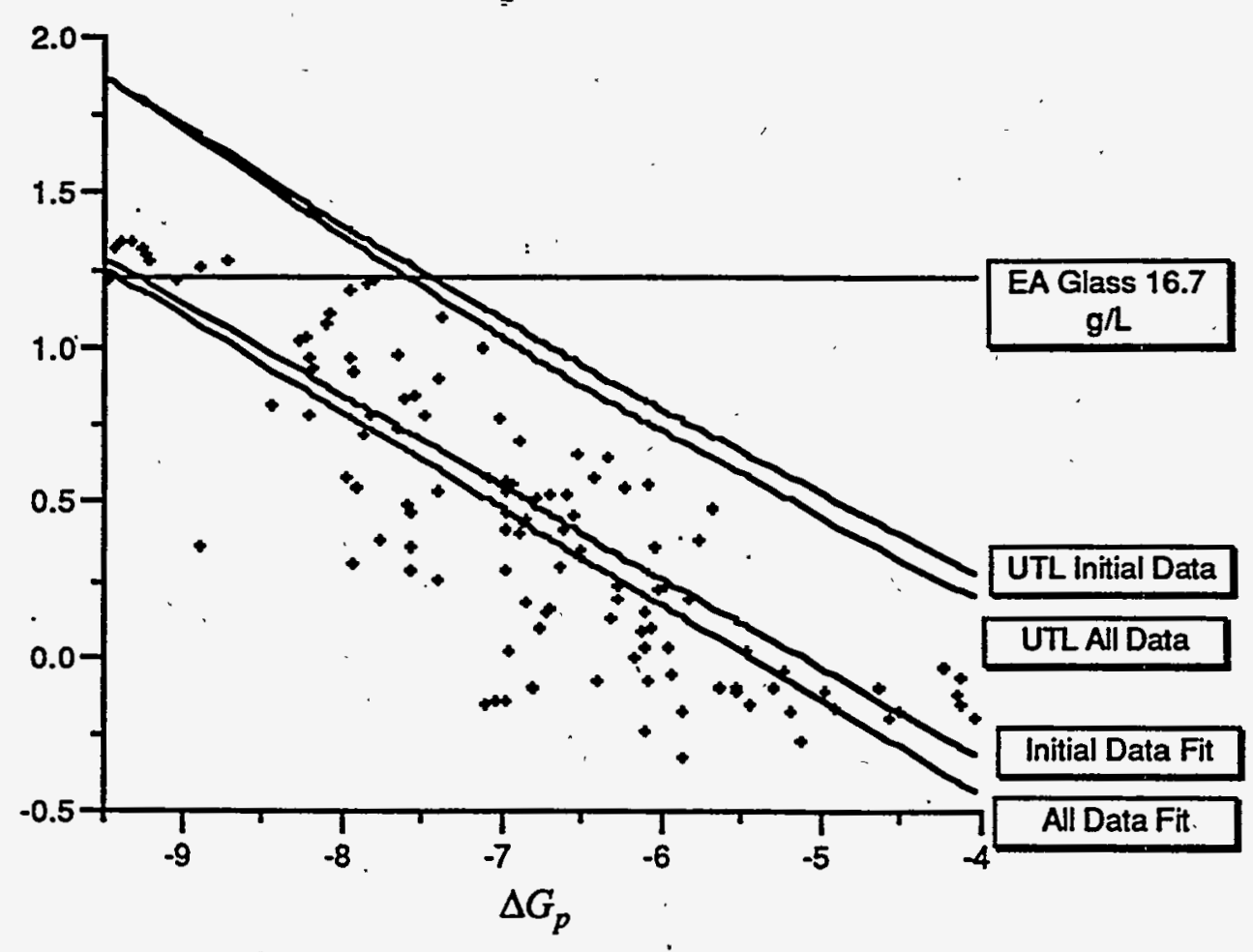

